\title{
Application of hue spectra fingerprinting during cold storage and shelf-life of packaged sweet cherry
}

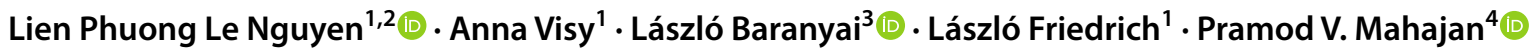

Received: 3 April 2020 / Accepted: 15 June 2020 / Published online: 23 June 2020

(c) The Author(s) 2020

\begin{abstract}
Presented work investigated the application of a new color analysis technique in post-harvest life of sweet cherry (Prunus avium L. 'Hudson'). The hue spectra fingerprinting creates a histogram of image colors by summarizing the saturation. The advantage of this calculation method is that vivid colors make peaks while neutral background color is eliminated without object segmentation. Partial Least Squares (PLS) regression was used to estimate reference parameters during $9 \mathrm{~d}$ cold storage at $10 \pm 0.5^{\circ} \mathrm{C}(\mathrm{RH}=90 \pm 1 \%)$ and following $2 \mathrm{~d}$ shelf-life at $20 \pm 0.5^{\circ} \mathrm{C}$. The reference parameters of respiration, weight loss, fruit firmness and total soluble solid (TSS) content were measured. Samples were split into seven groups according to the number of perforations of polypropylene film and fructose concentration of moisture absorber. It was observed that parameters TSS and fruit firmness were the most sensitive to the length of storage. Weight loss was affected significantly by packaging. All reference parameters were estimated by PLS model with $\mathrm{R}^{2}>0.917$, but weight loss and respiration obtained high estimation error of RMSE $\%=48.02 \%$ and $11.76 \%$, respectively. TSS and fruit firmness prediction were successful with RMSE $\%=0.84 \%$ and $1.85 \%$, respectively. Desiccation and color change of peduncle became visible in the green range of hue spectra. Color change of red fruit was observed with decreasing saturation in the red range of hue spectra. Our findings suggest that hue spectra fingerprinting can be a useful nondestructive method for monitoring quality change of sweet cherry during post-harvest handling and shelf-life.
\end{abstract}

Keywords Surface color · Prunus avium L. · Computer vision · Digital image processing

\section{Introduction}

Sweet cherry (Prunus avium L.) is very popular and consumed as fresh fruit. The characteristic red color is the major quality attribute and primarily affects consumer acceptance [1-3]. Additionally, cherry contains valuable bioactive compounds, mainly anthocyanins $[4,5]$. The quality assignment based on visual observation is supported by the fact that

László Baranyai

Baranyai.Laszlo@etk.szie.hu

1 Department of Refrigeration and Livestock Product Technology, Szent István University, Budapest, Hungary

2 Institute of Biotechnology and Food Technology, Industrial University of Ho Chi Minh City, Ho Chi Minh, Vietnam

3 Department of Physics and Control, Szent István University, Budapest, Hungary

4 Department of Horticultural Engineering, Leibniz Institute for Agricultural Engineering and Bioeconomy (ATB), Potsdam, Germany anthocyanins are the red color pigments of cherry and also contribute to the antioxidant capacity of fruit [6]. Cherry is highly perishable produce and its shelf-life is typically limited in weeks [7]. During the supply chain, appearance changes rapidly by means of color, gloss, surface pitting and peduncle browning [8]. Especially the latter parameter is interesting since peduncle browning was found to reflect changes in water status of peduncle itself and fruit body as well. As a result, color measurements shall include evaluation of both fruit body and peduncle.

The optimum harvest date was estimated by utilizing color for sweet cherry 'Burlat' [9], and using pigment specific spectral parameters for 'Samba' and 'Bellise' [10]. Genetic algorithm utilizing reflectance spectra, including visible range from $580 \mathrm{~nm}$, was able to detect insect infestation of tart cherry above $81 \%$ accuracy [11]. Significant change of fruit color was observed for 'Napoleon' cherry during cold storage by means of CIELAB $a^{*}, b^{*}$ and chroma, but no correlation was found with anthocyanin content [12]. It was observed, that large and more colored 
sweet cherry 'Kordia' reached higher amount of edible part with better sugar/acid ratio [13]. More colored fruits were found to be larger ( $>8 \mathrm{~g},>\varnothing 26 \mathrm{~mm}$ ) and have more soluble solid content (SSC), sugars and anthocyanins compared to less colored ones. On the other hand, neither color nor fruit size affected vitamin $\mathrm{C}$ content and amount of total phenolic compounds. Additionally, no significant difference was found in firmness between fruit of different color [13]. The sweet cherry 'Brooks' was tested with sensory analysis by trained panel and consumers during 1997-1999 [14]. Trained panel distinguished 4 groups of cherry of different peel color according to the fruit sweetness and cherry flavor intensity. Untrained consumers preferred cherry with SSC $>16 \%$ and their answers shown significant correlation between peel color and all sensory attributes (sweetness, sourness, cherry flavor intensity). Both sweetness and flavor intensity correlated the best with chroma $(r=-0.976$ and -0.995 , respectively) while sourness obtained the highest correlation with hue among visual attributes $(r=0.906)$. According to the results for 'Brooks' and 'Bing' sweet cherry, Crisosto et al. [1] concluded that growers should measure SSC at different fruit color to optimize harvesting. The relationship between instrumentally measured color and anthocyanin concentration was evaluated for four cherry cultivars [15]. Standard CIELAB parameters chroma and hue significantly correlated with anthocyanin concentration but not with total phenols. Pre-harvest color rating method was developed for cherry by Wang et al. [16]. The computer vision system calculated ratings were compared to manual scores. The correct rating was over $85 \%$ consistently. The major obstacle of surface reflections and inconsistent light in the canopy was solved with camera flash. Finally, seven levels of peel color were distinguished successfully by the system [16]. Instrumental color analysis usually results in standard CIELAB parameters $\mathrm{L}^{*}, \mathrm{a}^{*}$ and $\mathrm{b}^{*}$ [9]. Technology specific color indices, such as browning index, can be calculated from both standard $a^{*}, b^{*}$ and changing intensity of images [17]. Fruit color is typically represented by derived parameters of $a^{*}$ and $b^{*}$, namely hue and chroma [3, 13-15, 18]. The relationship between SSC and visual appearance plays an important role in determining consumer acceptance of cherry fruit [1]. However, the number of studies evaluating the mathematical relationship between color and reference parameters of cherry is still limited.

Above mentioned studies show that sweet cherry color, measured on fruit surface, reflects fruit quality and has firm relationship with some key parameters such as anthocyanin concentration, sweetness, fruit specific flavor. Besides fruit surface color, peduncle (stem) color is also a freshness indicator influencing directly the consumer acceptance. Therefore all visible parts of harvested fruit should be included in the evaluation. In this context, the aim of this presented work was to apply hue spectra fingerprinting method on color images to estimate common reference parameters. Cold storage and shelf-life was followed in the experiment to induce changes and evaluate feasibility of the method in monitoring quality.

\section{Materials and methods}

\section{Materials}

Sweet cherries (Prunus avium L. 'Hudson') were harvested at the commercial maturity stage from the farm of Leibniz Institute for Agricultural Engineering and Bioeconomy (Marquardt, Germany) in July, 2019. Collected samples were transported to the laboratory within an hour. Cherries of approximately $\varnothing 25 \mathrm{~mm}$ size, free from damage, greenish stems and uniform external appearance were selected. Fruit were precooled to $10^{\circ} \mathrm{C}$.

Samples of $200 \pm 5 \mathrm{~g}$ were packed in polypropylene tray of $16 \mathrm{~cm}$ length $\times 11 \mathrm{~cm}$ width $\times 5 \mathrm{~cm}$ depth. Trays were randomly separated into 7 groups (Table 1). One group with open tray served as control during the experiment. The remaining six groups were covered with bi-axially oriented polypropylene film of $25 \mu \mathrm{m}$ thickness. The lid film was perforated with one or three micro-perforations of $\varnothing 0.7 \mathrm{~mm}$ using a needle. As a result, three groups were perforated with one hole and other three groups with three holes. Additionally, each perforation group was randomly split into three sub-groups. Different absorbers were applied for the sub-groups in order to control humidity inside the package. This is important because the temperature fluctuation during storage or transport causes moisture condensation inside the packages leading to high humidity surrounding the produce, favoring for microbial development [19, 20]. Fructose is hygroscopic and absorbs moisture from the package headspace therefore avoids near saturation condition in package. Cellulose fiber with $30 \%$ and $90 \%$ of fructose was selected because moisture uptake by absorber was proportional to the concentration of fructose embedded in the FruitPad

Table 1 Sample groups of cherry according to packaging and moisture absorber

\begin{tabular}{llll}
\hline Absorber & \multicolumn{3}{l}{ Micro-perforations } \\
\cline { 2 - 4 } & Open tray & 1 & 3 \\
\hline None & Control & & \\
None & & $1-\mathrm{NA}$ & $3-\mathrm{NA}$ \\
$30 \%$ fructose & & 1-FP30 & $3-\mathrm{FP} 30$ \\
$90 \%$ fructose & & 1-FP90 & $3-\mathrm{FP} 90$ \\
\hline
\end{tabular}

Group names show number of perforations, followed by: $N A$ no absorber, FP30 FruitPad with 30\% fructose, FP90 FruitPad with $90 \%$ fructose 
(McAirLaid's Vliesstoffe GmbH, Steinfurt, Germany) [21]. Moisture sorption was expressed as g water per g FruitPad.

The seven groups were expected to show different behavior over storage and help evaluation of hue spectra fingerprinting with wide range of data. All samples were stored at $10 \pm 0.5^{\circ} \mathrm{C}$ with relative humidity (RH) of $90 \pm 1 \%$ for $9 \mathrm{~d}$ and additional $2 \mathrm{~d}$ for shelf-life at ambient temperature of $20 \pm 0.5^{\circ} \mathrm{C}$. Measurements were performed upon arrival to laboratory $(0 \mathrm{~d})$, during cold storage $(3,6$ and $9 \mathrm{~d})$ and subsequent shelf-life (11 d).

\section{Reference measurements}

\section{Headspace gas concentration}

Three trays per group were randomly withdrawn from storage and the headspace gas concentration of $\mathrm{O}_{2}$ and $\mathrm{CO}_{2}$ in the package were measured. One needle was pierced into the package, then gases were pumped out through the needle and injected into gas analyzer (CheckMate3, Dansensor, Denmark). Results were expressed as percentage of $\mathrm{O}_{2}$ and $\mathrm{CO}_{2}$ inside the package [22].

\section{Respiration}

Carbon dioxide release from the cherries was measured in a closed respiratory system over $3 \mathrm{~h}$ in closed Perspex ${ }^{\circledR}$ cylinders with infra red sensors (FYA600CO2, Ahlborn Messund Regeltechnik GmbH, Holzkirchen, Germany). From the increase in $\mathrm{CO}_{2}$ concentration over time, respiration activity was calculated as milligram of $\mathrm{CO}_{2}$ produced per kilogram of fruit in $1 \mathrm{~h}\left(\mathrm{mg} \mathrm{CO}_{2} \mathrm{~kg}^{-1}\right.$ fruit $\left.\mathrm{h}^{-1}\right)[8]$.

\section{Weight loss}

Weight loss was determined by weighing the cherries at the beginning of the experiment and each interval with an electronic balance (BP 210 S, Sartorius AG, Göttingen, Germany). Results were expressed as percentage loss of initial readings according to Serrano et al. [3].

\section{Firmness}

Fruit firmness was measured with TA.XT.plus Texture Analyzer (Stable Microsystems, UK) instrument. Firmness of cherry was determined using a spherical steel probe $(\varnothing 6.35 \mathrm{~mm})$. Force, deformation and time data were recorded, from which firmness was calculated as the maximum force used to achieve $2 \%$ deformation of the fruit diameter [3].

\section{Total soluble solid content}

Total soluble solid (TSS; \%) content was obtained with a digital refractometer (ATAGO PR 1, Leo Kuebler GmbH, Karlsruhe, Germany) using freshly squeezed liquid according to Rux et al. [23].

\section{Digital image processing}

Images of Full HD size $(1920 \times 1080$ pixel $)$ were captured using a color camera (Samsung WB350F). Optical zoom of 4.0 was adjusted. Samples of $8-12$ fruit were placed on white background at the same time. This background was used as color reference and all images were adjusted to have the same white balance. Pictures were processed using GNU Octave (version 4.4.1) software [24]. After white balance adjustment, the whole picture was scanned and hue spectra fingerprint was collected as summary of saturation for all hue values (Eq. 1).

$F(i)=\frac{1}{N} \sum_{x, y} S(x, y)_{S(x, y)>0.05}^{H(x, y)=i}$

where $N$ is the number of pixels, $F(i)$ is the value for hue angle $i, S(x, y)$ is the saturation value for pixel at coordinates $x$ and $y$, and $H(x, y)$ is the hue angle for pixel at coordinates $x$ and $y$. Hue and saturation are calculated for each pixel according to the following equations (Eq. 2).

$H=\tan ^{-1} \frac{b}{a}, S=\sqrt{a^{2}+b^{2}}, a=R-\frac{G+B}{2}, b=\frac{\sqrt{3}(G-B)}{2}$

where $H$ is the hue angle in $0-360^{\circ}, S$ is the saturation scaled in $0-1$, and R, G, B are red, green and blue intensity values, respectively. The Octave function atan 2 can avoid failure with division by zero.

The advantage of the calculation is that neutral colors, such as black and white, have zero saturation, therefore they are not visible on spectra. In order to remove potential noise, the threshold value of 5\% was applied with $S(x, y)>0.05$. As a result, $F(i)$ has peaks at the observed colors and zero value for others. This data vector has 360 elements for hue angle in the range of $0-360^{\circ}$. Color change is expected to move peaks and changing homogeneity will alter width of peaks. This hue spectra is the color representation of the picture, like a fingerprint. This data vector can be processed with all mathematical tools used in chemometry and spectra analysis. Since neutral pixels of low saturation are removed, computation can be 
fast because there is no need for segmentation and object recognition.

\section{Statistical evaluation}

The statistical software of R (version 3.6.2, R Foundation for Statistical Computing, Vienna, Austria) was used with package Partial Least Squares and Principal Component Regression (PLS, version 2.7-2) [25]. Groups were compared with Analysis of Variances (ANOVA) and significant differences were tested with Tukey's post-hoc test $(\mathrm{p}<0.05)$. Effectiveness of PLS prediction was evaluated with determination coefficient $\left(\mathrm{R}^{2}\right)$ and root mean squared error (RMSE). Figures represent data with mean value and standard deviation (SD).

\section{Results}

\section{Hue spectra}

Sweet cherry has dark red color on fruit surface and its stem is green (Fig. 1a), therefore two color segments were expected to show peaks on the spectra. It was observed, that peaks became smaller due to the color change from vivid red or green toward dark color and they also moved along hue angle during storage and shelf-life (Fig. 1b). Especially the stem, changed its color and moved peak from green toward brown.

Hue spectra was used to build PLS prediction models for reference parameters. The PLS loadings confirmed that data below $100^{\circ}$ and above $320^{\circ}$ contributed to the models.
Fig. 1 Sweet cherry sample arranged in front of the camera (a) and average hue spectra at the beginning and end of the experiment (b)

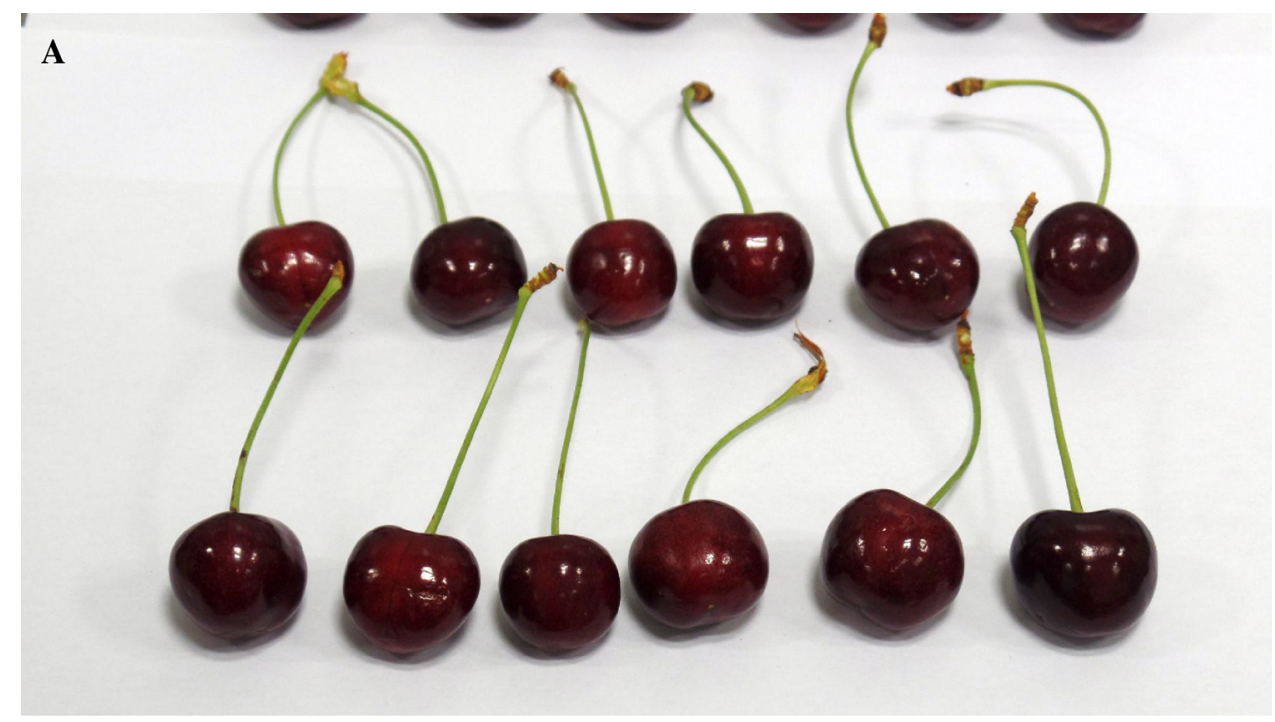

B

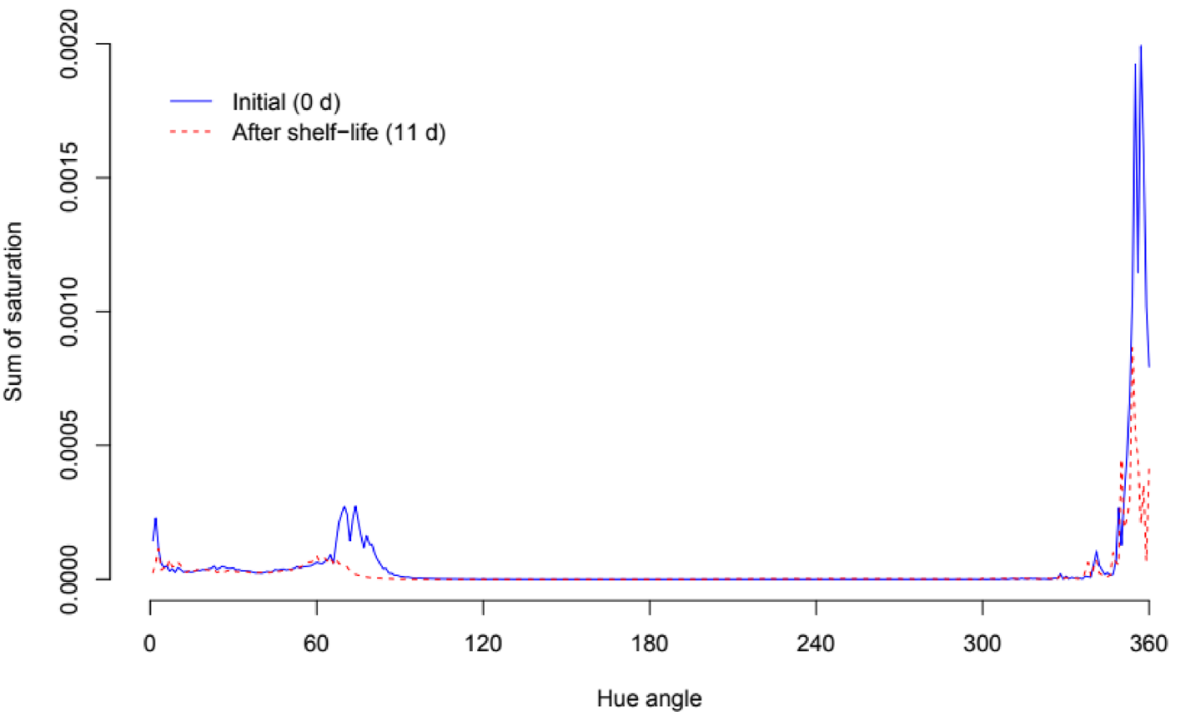




\section{Headspace gas concentration and respiration}

Headspace $\mathrm{O}_{2}$ concentration decreased to $15.5 \%$ during cold storage and finally to $10.0 \%$ after shelf-life. At the same time, $\mathrm{CO}_{2}$ concentration increased to $3.6 \%$ during cold storage and reached approximately $10.0 \%$ after shelf-life (data not shown).

The respiration rate for all samples increased during the experiment (Fig. 2). Groups overlapped each other during cold storage, and separated according to the number of perforations in shelf-life. Considering all respiration rate data, there was significant difference among certain perforation groups (ANOVA F $=9.442, p<0.001$ ). Moisture absorber did not contribute significantly to the changes of respiration rate.

The respiration rate increased rapidly at ambient temperature, after $9 \mathrm{~d}$. As a result, readings did vary from 14.74 to $47.89 \mathrm{mg} \mathrm{CO}_{2} \mathrm{~kg}^{-1} \mathrm{~h}^{-1}$. PLS model was created to estimate respiration data based on surface color represented by hue spectra. The number of latent variables (LV) was adjusted to 30 , which is $8.33 \%$ of the data vector. Data did not distribute uniformly within the range, but model obtained good result with $\mathrm{R}^{2}=0.917$ and $\mathrm{RMSE}=2.42 \mathrm{mg} \mathrm{CO}_{2} \mathrm{~kg}^{-1} \mathrm{~h}^{-1}$. Figure 3 shows the PLS prediction result in comparison with collected data. There is some fluctuation, but majority of data at respiration below $22 \mathrm{mg} \mathrm{CO}_{2} \mathrm{~kg}^{-1} \mathrm{~h}^{-1}$ was estimated well and resulted in the relative prediction error of RMSE $\%=11.76 \%$.

\section{Fruit firmness}

The firmness of all samples decreased slightly throughout 9 $\mathrm{d}$ of cold storage, followed by a stronger decline in shelf-life, particularly for control fruit (Fig. 4). Control fruit became the softest and packaging could slow down softening process. There was difference between certain groups, but no clear separation was found according to the number of perforation. Observed behavior of cherry firmness is in agreement with literature [26]. Moisture absorber did not affect cherry firmness significantly.

PLS model was created to estimate fruit firmness based on the hue spectra of color images $(\mathrm{LV}=30)$. The model fits well to data points $\left(R^{2}=0.971\right)$ with small error of $\mathrm{RMSE}=0.024 \mathrm{~N}$. Prediction result is presented in comparison with collected data on Fig. 5. Small fluctuation of prediction is visible, but model accuracy is very good with RMSE $\%=1.85 \%$. Firmness was found to have strong linear correlation with total soluble solid content $(r=-0.924)$.

\section{Total soluble solid content}

Total soluble solid content of sweet cherry increased gradually over cold storage period for all samples, later on more rapidly when moved to ambient temperature $\left(20 \pm 0.5^{\circ} \mathrm{C}\right)$. There was high variability within sample groups and average readings were close (Fig. 6). Comparing the initial and final values, significant differences can be observed among certain groups. However, no clear distinction can be made due to the large overlap of data. Obtained results of TSS are in agreement with literature [7]. The range of TSS accounts for $11-20^{\circ}$ Brix and it typically remains almost in the same range during cold storage or modified atmosphere packaging.

PLS model was created to estimate TSS content of sweet cherry $(L V=30)$ based on hue spectra (Fig. 7). This model fits data with $R^{2}=0.960$, and the prediction error of
Fig. 2 Respiration rate of sweet cherry during $9 \mathrm{~d}$ cold storage and $2 \mathrm{~d}$ shelf-life

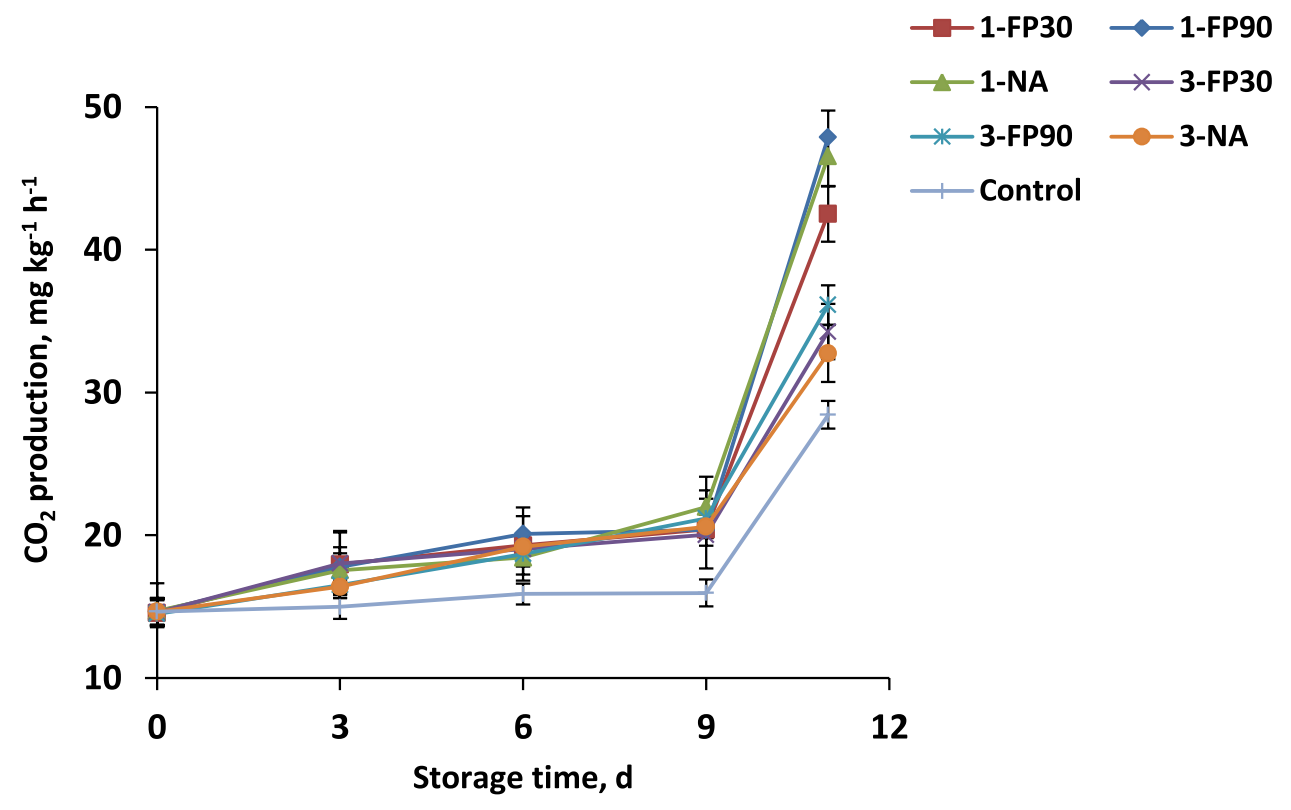


Fig. 3 PLS prediction result of respiration rate based on hue spectra

Fig. 4 Firmness of sweet cherry during $9 \mathrm{~d}$ cold storage and $2 \mathrm{~d}$ shelf-life
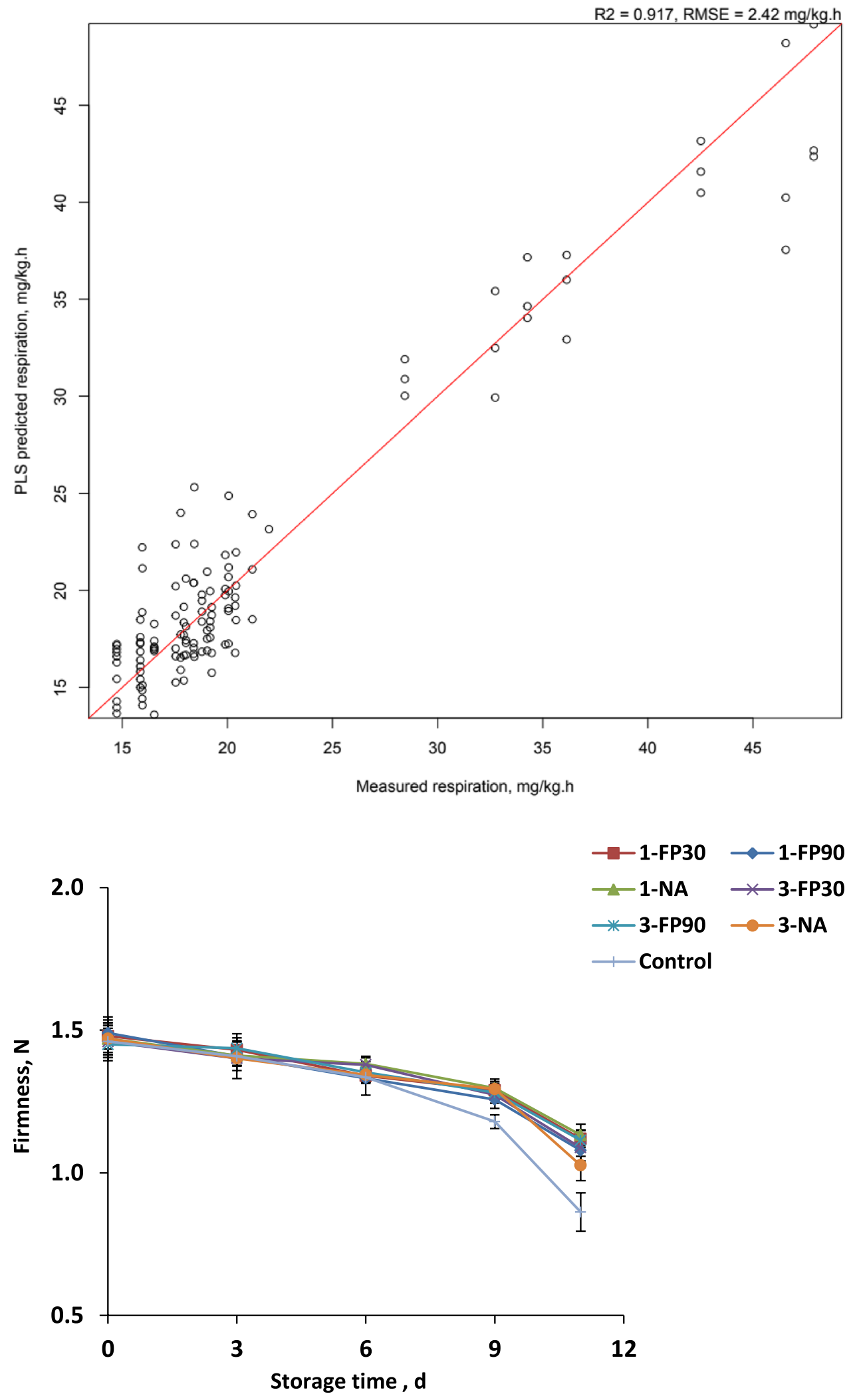
Fig. 5 PLS prediction result of fruit firmness based on hue spectra
Fig. 6 Total soluble solid content of sweet cherry during $9 \mathrm{~d}$ cold storage and $2 \mathrm{~d}$ shelf-life
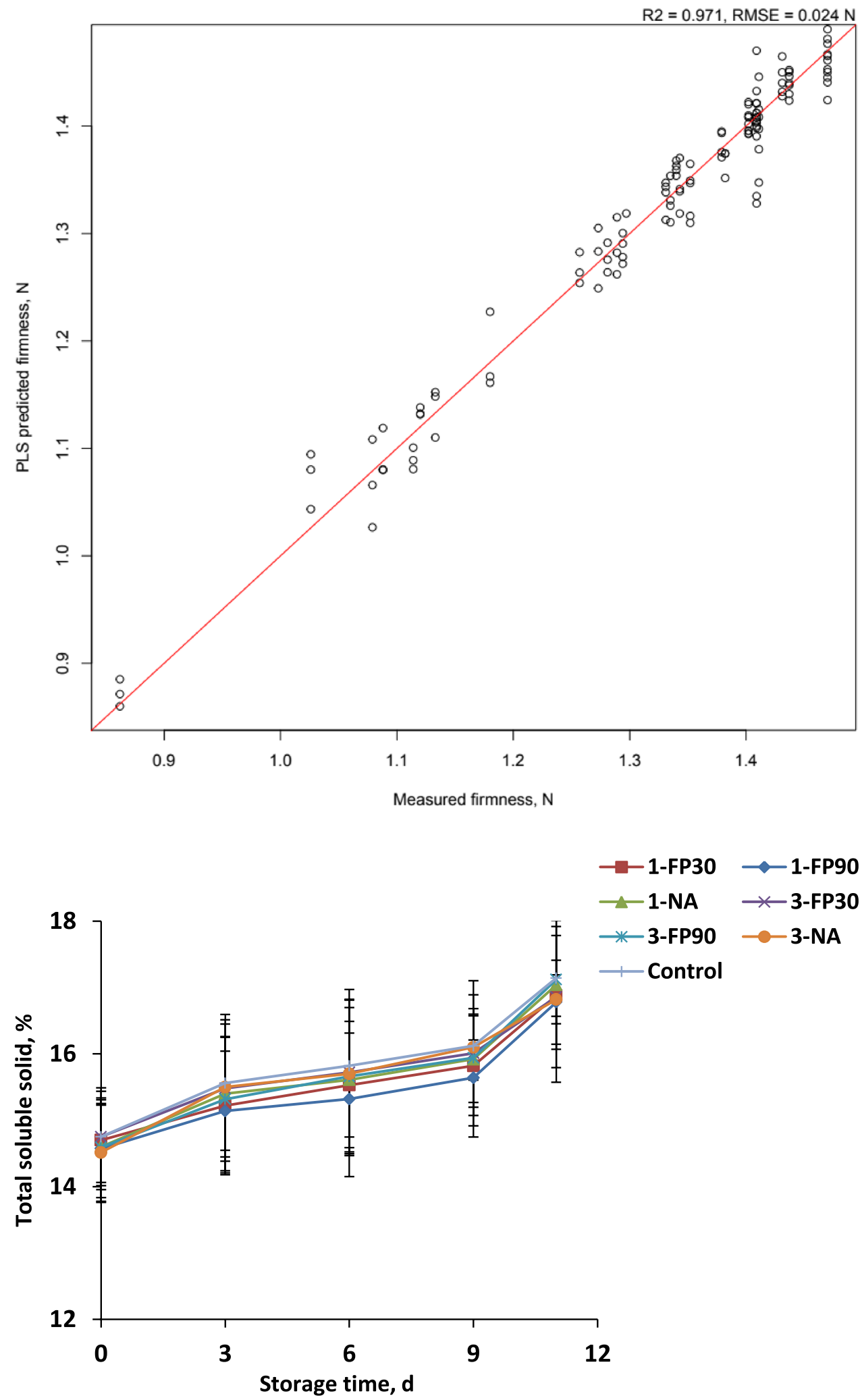

RMSE $=0.13 \%$. The relative error was the smallest among other reference parameters with $\mathrm{RMSE} \%=0.84 \%$. Besides the strong relationship with fruit firmness, TSS correlated significantly with respiration $(r=0.827)$.

\section{Weight loss}

The weight loss of all samples increased during cold storage and shelf-life (Fig. 8). There was significant difference 
Fig. 7 PLS prediction result of total soluble solid content based on hue spectra

Fig. 8 Weight loss of sweet cherry during $9 \mathrm{~d}$ cold storage and $2 \mathrm{~d}$ shelf-life
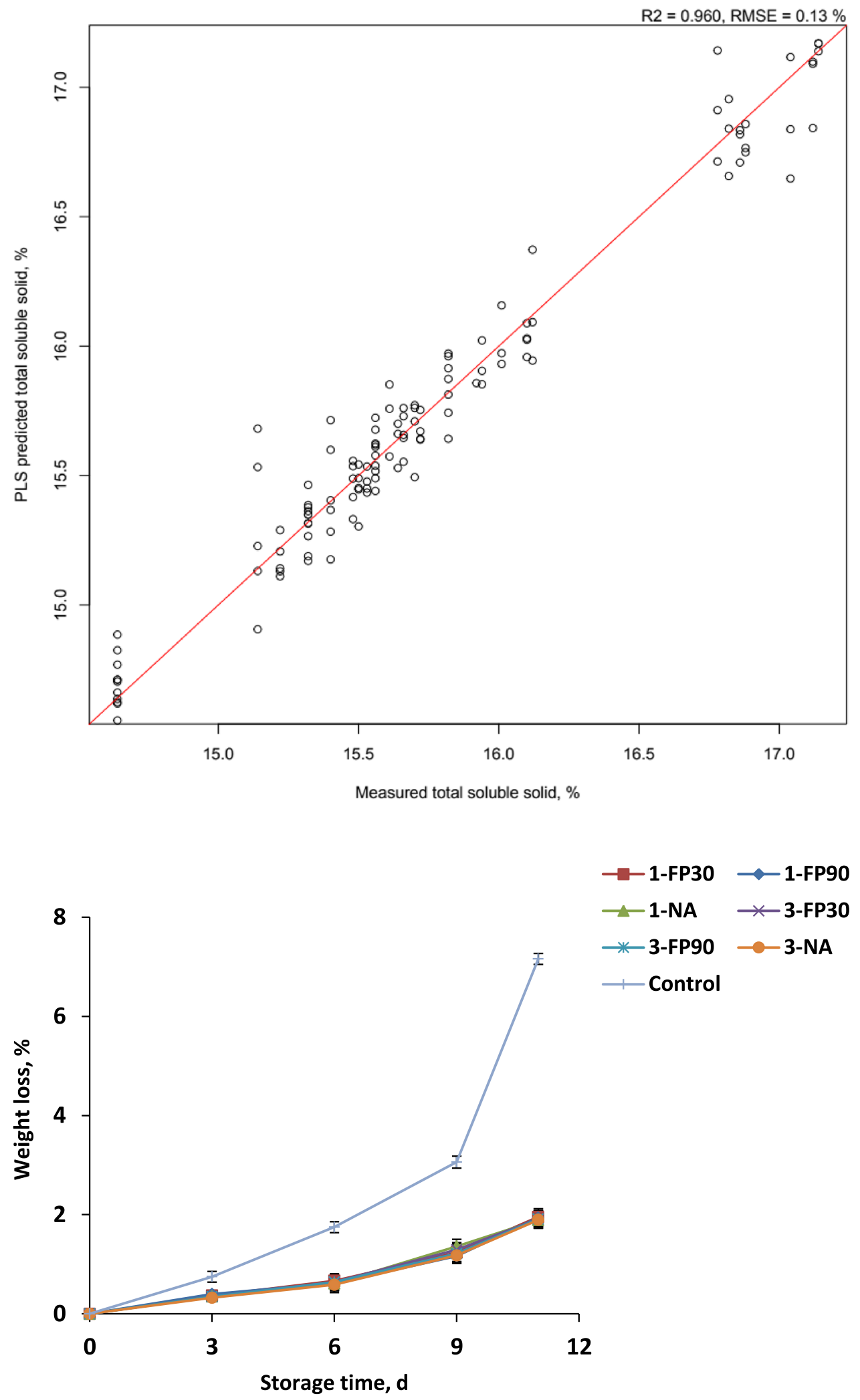
Fig. 9 PLS prediction result of weight loss based on hue spectra

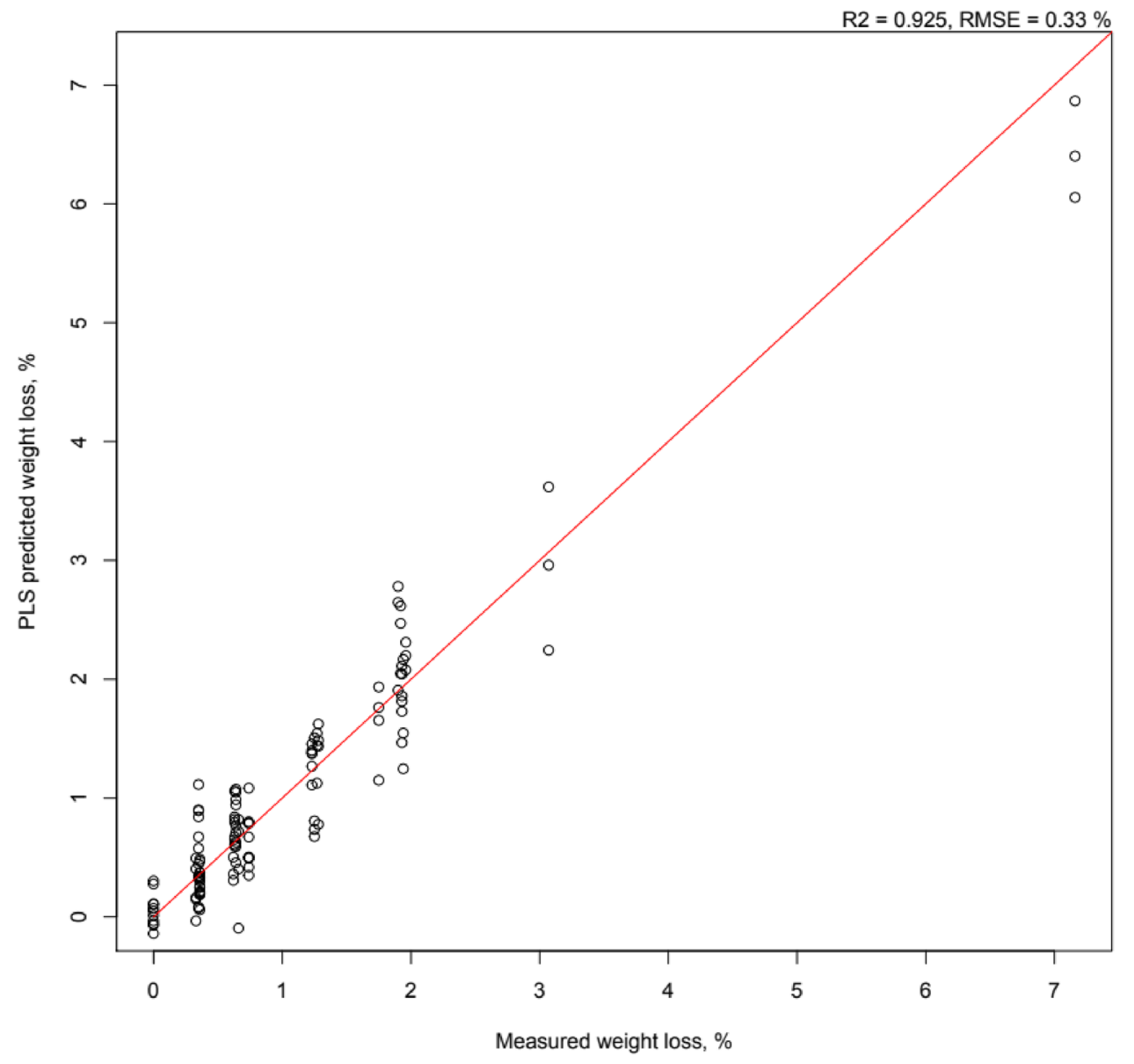

between control group and others in any packaging. Fruit covered with perforated foil suffered weight loss of $0.64 \%$ within $6 \mathrm{~d}$ and $1.92 \%$ after shelf-life, while control fruit obtained $1.75 \%$ within first $6 \mathrm{~d}$ and $6.97 \%$ final value after shelf-life.

There was significant difference in weight loss between control and the other groups (ANOVA $F=96.434$, $\mathrm{p}<0.001)$. Significant correlation was observed between weight loss and firmness $(r=-0.867)$ and TSS $(r=0.745)$.

Weight loss was also estimated by PLS model $(\mathrm{LV}=30)$ based on hue spectra (Fig. 9). The determination coefficient was high $\left(\mathrm{R}^{2}=0.925\right)$ but estimation error reached $\mathrm{RMSE}=0.33 \%$. Especially at low values, the prediction error is high resulting in the relative error of $\mathrm{RMSE} \%=48.02 \%$. According to these result, weight loss could not be estimated using surface color.

\section{Role of moisture absorber}

The FruitPad absorbed moisture from the environment of fruit (Fig. 10). No sign of water condensation was observed for packages with FruitPad, whereas condensed water occurred on the inner part of lid film at $5 \mathrm{~d}$ of cold storage for the packs without FruitPad. Small fluctuation of temperature can result in condensation with high $\mathrm{RH}$, its prevention is critical [7]. Fructose concentration of absorber did not result significant effect on measured parameters. Observed differences in sorption curves (Fig. 10) show the response of absorber to environment inside packaging.

As a result, the combination of perforations and moisture absorbers provided adequate packaging to prolong shelf-life of sweet cherry.

\section{Comparison of parameters}

The reference parameters showed strong relationship to each other according to Pearson correlation coefficient (Table 2). The agreement of parameters clearly indicates the quality change of sweet cherry during the experiment.

There was difference among the reference parameters in terms of response to storage time, number of perforations on packaging and absorber concentration. According to the Fisher score of ANOVA, parameters TSS and firmness were more sensitive to the length of storage, while weight loss showed clear difference based on packaging (Table 3).

All PLS prediction models used the same number of latent variables $(\mathrm{LV}=30)$. The number of latent variables is only $8.33 \%$ of the available hue spectra data. All models 
Fig. 10 Moisture sorption of FruitPad used in packaging

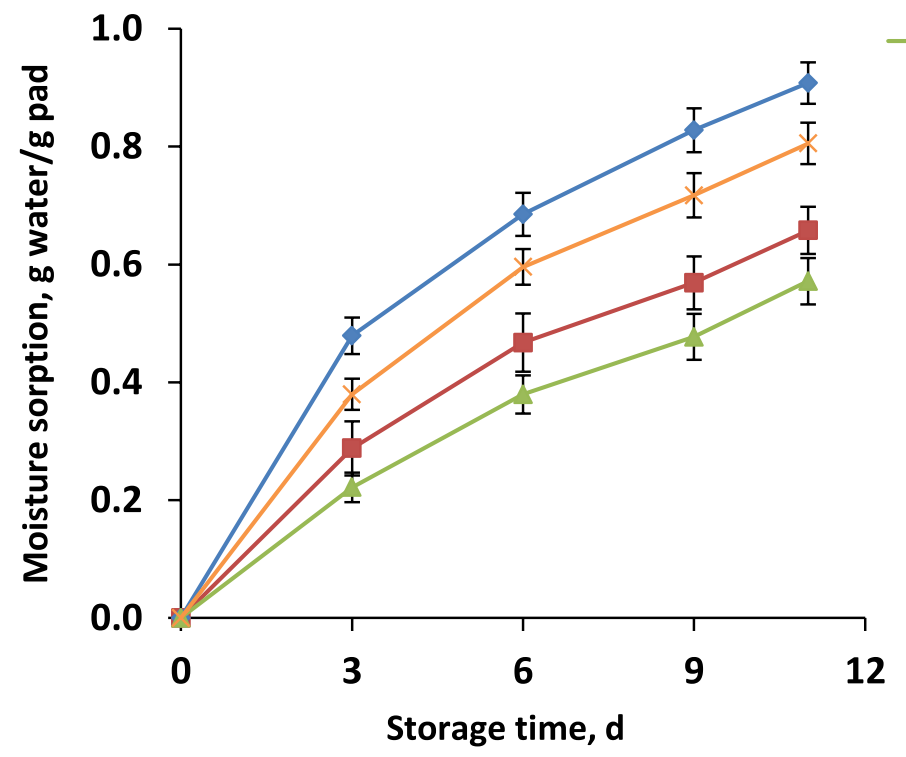

reached high determination coefficient $\left(\mathrm{R}^{2}>0.917\right)$, but two models can be considered successful with the relative prediction error of RMSE\% $<2.00 \%$. Collected data represent one harvest and season, therefore validation was performed according to the sample groups (Table 1). PLS models were created excluding data of a specific group and estimation of parameters of selected group was used for validation. Evaluation of firmness prediction model by groups is summarized in Table 4 . The total number of evaluated pictures were 124, including the initial 12 taken
Table 3 Sensitivity and prediction results of reference parameters

Table 4 Firmness prediction model and validation on sample groups

\begin{tabular}{|c|c|c|c|c|c|c|}
\hline \multirow[t]{2}{*}{ Reference parameter } & \multicolumn{3}{|c|}{ ANOVA F } & \multicolumn{3}{|c|}{ PLS regression $(\mathrm{LV}=30)$} \\
\hline & Time & Packaging & Absorber & $\mathrm{R}^{2}$ & RMSE & RMSE (\%) \\
\hline Total soluble solid & 883.495 & 10.070 & 8.772 & 0.960 & 0.13 & 0.84 \\
\hline Firmness & 806.993 & 17.049 & 0.024 & 0.971 & 0.024 & 1.85 \\
\hline Weight loss & 577.233 & 96.434 & 0.014 & 0.925 & 0.33 & 48.02 \\
\hline Respiration & 204.302 & 9.442 & 0.006 & 0.917 & 2.42 & 11.76 \\
\hline
\end{tabular}

\begin{tabular}{|c|c|c|c|c|c|c|c|}
\hline \multirow[t]{2}{*}{ Sample group } & \multirow[t]{2}{*}{$\mathrm{N}$} & \multicolumn{3}{|c|}{ Calibration* } & \multicolumn{3}{|c|}{ Validation** } \\
\hline & & $\overline{\mathrm{R}^{2}}$ & RMSEC & RMSEC (\%) & $\overline{\mathrm{R}^{2}}$ & RMSEV & RMSEV (\%) \\
\hline Control & 20 & 0.976 & 0.019 & 1.51 & 0.450 & 0.153 & 12.36 \\
\hline 1-NA & 13 & 0.980 & 0.020 & 1.62 & 0.674 & 0.086 & 6.36 \\
\hline 3-NA & 18 & 0.978 & 0.021 & 1.64 & 0.734 & 0.072 & 6.13 \\
\hline 1-FP30 & 15 & 0.978 & 0.021 & 1.66 & 0.796 & 0.084 & 6.15 \\
\hline 1-FP90 & 15 & 0.983 & 0.019 & 1.47 & 0.657 & 0.088 & 6.54 \\
\hline 3-FP30 & 15 & 0.975 & 0.022 & 1.82 & 0.755 & 0.079 & 6.73 \\
\hline 3-FP90 & 16 & 0.982 & 0.019 & 1.45 & 0.640 & 0.115 & 8.78 \\
\hline
\end{tabular}

*Calibration model is built excluding selected group, model is tested on the others

** Validation is performed only on the selected group 
Table 5 Total soluble solid content prediction model and validation on sample groups

\begin{tabular}{|c|c|c|c|c|c|c|c|}
\hline \multirow[t]{2}{*}{ Sample group } & \multirow[t]{2}{*}{$\mathrm{N}$} & \multicolumn{3}{|c|}{ Calibration* } & \multicolumn{3}{|c|}{ Validation** } \\
\hline & & $\overline{\mathrm{R}^{2}}$ & RMSEC & RMSEC (\%) & $\overline{\mathrm{R}^{2}}$ & RMSEV & RMSEV (\%) \\
\hline Control & 20 & 0.974 & 0.11 & 0.69 & 0.438 & 0.55 & 3.49 \\
\hline 1-NA & 13 & 0.976 & 0.10 & 0.64 & 0.526 & 0.48 & 3.02 \\
\hline 3-NA & 18 & 0.967 & 0.12 & 0.78 & 0.847 & 0.32 & 2.00 \\
\hline 1-FP30 & 15 & 0.967 & 0.12 & 0.77 & 0.782 & 0.34 & 2.15 \\
\hline 1-FP90 & 15 & 0.979 & 0.10 & 0.60 & 0.758 & 0.41 & 2.69 \\
\hline 3-FP30 & 15 & 0.971 & 0.11 & 0.72 & 0.729 & 0.36 & 2.27 \\
\hline 3-FP90 & 16 & 0.969 & 0.12 & 0.74 & 0.700 & 0.35 & 2.22 \\
\hline
\end{tabular}

*Calibration model is built excluding selected group, model is tested on the others

*** Validation is performed only on the selected group before separation of sample groups. Calibration models obtained high $\mathrm{R}^{2}$ with the average of 0.979 and low average relative error of RMSEC $\%=1.60 \%$. Validation of groups reached lower average $\mathrm{R}^{2}$ of 0.672 and higher average relative error of RMSEV $\%=7.58 \%$. Especially validation of control group, stored in open tray, was less successful with RMSEV $\%=12.36 \%$.

Evaluation of PLS model performance on TSS prediction is presented in Table 5. Calibration models obtained high $\mathrm{R}^{2}$ with average of 0.972 and low average relative error of RMSEC $\%=0.71 \%$. Similar to firmness validation results, TSS validation also reached lower $\mathrm{R}^{2}$ and higher error. The determination coefficient fell to similar average of $\mathrm{R}^{2}=0.683$ like that of firmness, but relative error of validation did not increase so high with average of RMSEV $\%=2.52 \%$. All group validation achieved small relative error of RMSEV\% $<3.5 \%$.

Total soluble solid content and fruit firmness prediction obtained promising results in calibration (Table 3). Validation confirmed the potential of TSS prediction using hue spectra fingerprinting (Table 5). Firmness prediction achieved error above 5\% but average was less than $10 \%$ (Table 4). Both TSS and firmness estimation based on hue spectra of fruit and peduncle can be recommended for monitoring, but TSS model outperformed all others.

\section{Discussion}

Sweet cherry is very sensitive, perishable produce with short shelf-life. Its storage potential is low and limited in few weeks even under optimal conditions [27]. Consequently, several studies investigated potential techniques to prolong postharvest life. Near freezing temperature of $-1.5^{\circ} \mathrm{C}$ and $-1.9^{\circ} \mathrm{C}$ were used to maintain physicochemical parameters of sweet cherry 'Hongdeng' and 'Lapins', respectively [18]. This cold storage obtained better firmness, TSS, acidity and decrease weight loss for $100 \mathrm{~d}$ storage than that of $0{ }^{\circ} \mathrm{C}$ and $5{ }^{\circ} \mathrm{C}$. Near freezing temperature requires accurate control of $\pm 0.1{ }^{\circ} \mathrm{C}$ to decrease fluctuation and avoid damage induced by ice crystals. Storage temperature of $1{ }^{\circ} \mathrm{C}$ was found to be effective in control of biosynthesis of anthocyanins [28]. The combination of cold storage temperature and modified atmosphere packaging was able to delay the ripening according to firmness, weight loss and color change [3]. Sweet cherry stored at $1{ }^{\circ} \mathrm{C}$ and $\mathrm{RH}=90 \%$ (with additional $1 \mathrm{~d}$ shelf-life at $20^{\circ} \mathrm{C}$ ) responded sensitively to essential oils in modified atmosphere packaging. Natural antifungal agents of eugenol, thymol, menthol and eucalyptol affected significantly the changes of respiration, weight loss, chroma index and firmness [3]. In our work, the common physicochemical parameters, measured as reference, were in agreement with literature: respiration, soluble solid content, weight loss and firmness. Studies investigating cherry quality typically measure color as a quality index related to anthocyanins and ripeness. Color is also considered to be the most important parameter determining acceptability by consumers [2] Consumers are looking for cherry with red fruit color and green stem [1]. However, application of color measurement in estimation of quality parameters of cherry is still limited. Muskovics et al. [29] found exponential relationship between firmness and CIELAB hue angle $\left(R^{2}=0.923\right)$ for sweet cherry during fruit development and ripening. They found that hue angle of fruit surface change follows logistic curve within 30-70 d after anthesis for 'Alex', 'Carmen' and 'Krupnoplodnaja' cherry. The inflection point of the curve was suggested for characterizing the fruit development process. This firmness model is limited to the time of fruit development.

Crisosto et al. [1, 14] obtained significant correlation between appearance and sensory attributes of cherry. Four groups of cherry were made based on color as full light red, $50 \%$ bright red, full bright red and full dark red for 'Brooks', and salmon, red, mahogany, dark mahogany for 'Bing'. Reference parameters of TSS, titratable acidity, $\mathrm{pH}$, weight and firmness were found to be different for selected groups. Although authors concluded that red color and SSC $>16 \%$ were preferred the most by expert panel and consumers, 
no model was created for prediction. In another study, hue, chroma and brightness $\left(\mathrm{L}^{*}\right)$ changes during storage were in agreement with chemical (ascorbic acid content, total anthocyanins content), physical (weight loss, firmness) and sensory (juiciness, texture, acceptability) parameters according to reported statistical analysis [18]. ANOVA test was performed to evaluate contribution of storage temperature and storage time to consumer acceptance and sensory attributes. However, no further analysis of mathematical relationship with color was presented. Hue spectra fingerprinting obtained similar agreement among measured parameters and resulted in estimation models. Computer vision is able to measure color and its pattern on the whole visible surface to evaluate ripeness, detect defects $[16,30]$. Surface color analysis usually include removal of glaring reflection and segmentation of region of interest (fruit and stem) [16]. These procedures are not necessary with hue spectra fingerprinting, since low saturation areas (surface reflection, white or gray background) are removed due to the low saturation. The green stem was identified as one expectation of consumers [1], and it was proved to indicate water status and quality of sweet cherry fruit [8]. The water loss via peduncle was found to be around $40 \%$ at the beginning of shelf-life and decrease exponentially. Strong relationship was observed between water content and maximum photochemical efficiency $\left(\mathrm{F}_{\mathrm{v}} / \mathrm{F}_{\mathrm{m}}\right)$ during storage [8]. Authors concluded that water deficit contributes $73 \%$ to the reduction of the photochemical efficiency. Peduncle has low resistance to vapor transfer and causes much higher water loss than fruit body, therefore stem color change is an important freshness indicator and it should be included in the quality evaluation. In agreement with this demand, hue spectra includes all visible colors of the picture in analysis, like a color fingerprint. Our results are coincident with previous study on peduncle [8], since hue spectra showed peaks in green color range and those peaks changed during cold storage and shelf-life. Green peaks of the hue spectra moved to lower hue values and peak values decreased due to the lower saturation as stem lost its fresh green color. The PLS prediction models also obtained valuable loadings (model coefficients) in green and red color range. The previously reported color change of stem from green to brown was observed in this work as well.

Overbeck et al. [10] predicted optimal harvest date of sweet cherry 'Samba' and 'Bellise' with $\pm 2 \mathrm{~d}$ on the basis of NDVI (normalized chlorophyll index) and NAI (anthocyanin index) spectroscopic parameters. The Vis/NIR spectroscopy is able to predict SSC and fruit firmness, based on the specific pigment absorbance change during storage [31-33]. The advantage of spectroscopy is its high accuracy which is also reflected by the prediction quality (RMSE\% $<1 \%$ ). Hue spectra fingerprinting also covers the visible color range in 400-900 nm, depending on the camera sensor. Color camera offers limited color range and lower accuracy compared to a spectroscopy instrument, but on the other hand, is able to measure on the whole fruit surface and stem color as well. Colorimeter and spectrophotometer instruments collect data only from the selected small surface area. Due to the size limitation of this technique, typically fruit body color is measured, neglecting the stem color. Similarly to reflectance spectra, hue spectra was utilized in PLS models. Single type of PLS with $L V=30$ was used to apply one method to all parameters. The relatively high number of LV is probably the result of narrow peaks that change location, width and value with changing color.

Weight loss was predicted with good $\mathrm{R}^{2}=0.925$ but high relative error of RMSE $\%=48.02 \%$. The value of weight loss was small and moderately increased during cold storage and control fruit accelerated at ambient temperature. The significant correlation of weight loss with TSS and firmness indicate that fruit reached advanced ripening. The significant difference between open tray control and packaging groups shows the advantage of applied packaging (absorber and perforations). Control group exceeded accepted $3 \%$ of weight loss [34] already in cold storage, while packed fruit were below 2,00\% within $11 \mathrm{~d}$, including $2 \mathrm{~d}$ shelf-life. Observed weight loss and fruit behavior is similar to that of for carrot [35]. Moisture absorber did not affect significantly weight loss of sweet cherry.

Respiration obtained better estimation but still high relative error of RMSE $\%=11.76 \%$. Similar tendency was observed for respiration with small changes in cold storage and sharp increase in shelf-life. The distribution of data was not balanced, what is likely to contribute to the low prediction efficacy.

Fruit firmness decreased gradually and more rapidly after withdrawal to ambient temperature. Open tray control fruit obtained the smallest firmness values and had stronger decline than others in shelf-life. This behavior is in agreement with previous study on cherry [26]. The PLS calibration of fruit firmness estimation achieved the best $\mathrm{R}^{2}=0.971$ and small relative error of $\mathrm{RMSE} \%=1.85 \%$. Validation of firmness prediction model was less successful with RMSEV $\%=7.58 \%$, but still can contribute to quality monitoring.

Total soluble solid content showed similar tendency, changed gradually during cold storage and shelf-life. The calibration of TSS estimation achieved $\mathrm{R}^{2}=0.960$ and the best RMSE $\%=0.84 \%$. The TSS prediction model outperformed all others including good validation result of RMSEV $\%=2.52 \%$. It can be observed, that gradually changing reference parameters of fruit firmness and TSS obtained good prediction. Both parameters can be estimated using fruit and peduncle color.

The results are in agreement with literature in terms of the best prediction of TSS like the Vis/NIR analysis of fruit quality [32]. Our observations suggest that hue spectra 
fingerprinting is a useful and rapid method for color analysis based on the combination of digital image processing and chemometrics. This non-contact and nondestructive measurement can be applied in online sorting and commercial practice.

\section{Conclusions}

Hue spectra fingerprinting represented the color of sweet cherry fruit and peduncle as well. The peaks of specific colors moved position and became wider with changing fruit color, and peak values reduced with decreasing color saturation. The reference parameters of respiration, weight loss, firmness and total soluble solid (TSS) content were measured during the experiment. Firmness and TSS changed gradually and values were distributed more evenly than that of respiration and weight loss. This behavior affected probably the prediction quality of PLS models. Firmness and TSS obtained acceptable small relative error. Firmness obtained the best $\mathrm{R}^{2}=0.971$ and TSS obtained the best RMSE $\%=0.84 \%$. Both red and green color ranges contributed to prediction models confirming the importance of peduncle color in evaluation of fruit quality. Hue spectra fingerprinting can be suggested for rapid and nondestructive monitoring of fruit quality during postharvest processes and shelf-life.

Acknowledgements Open access funding provided by Szent István University. This work was supported by McAirLaid's Vliesstoffe GmbH (Steinfurt, Germany), who provided FruitPad for the experiments. The Project is supported by the European Union and co-financed by the European Social Fund (Grant Agreement No. EFOP-3.6.3VEKOP-16-2017-00005). This research was supported by the Ministry for Innovation and Technology within the framework of the Higher Education Institutional Excellence Program (NKFIH-1159-6/2019) in the scope of plant breeding and plant protection researches of Szent István University.

Author contributions LPLN: measurement, data analysis and manuscript editing. AV: control measurement and data analysis. LB: data analysis and manuscript editing. LF: manuscript editing. PVM: design of experiment and manuscript editing.

Data availability Not included, available upon request.

\section{Compliance with ethical standards}

Conflicts of interest Authors declare no conflict of interest.

Informed consent Not applicable.

Code availability Not included, R scripts are available upon request.

Open Access This article is licensed under a Creative Commons Attribution 4.0 International License, which permits use, sharing, adaptation, distribution and reproduction in any medium or format, as long as you give appropriate credit to the original author(s) and the source, provide a link to the Creative Commons licence, and indicate if changes were made. The images or other third party material in this article are included in the article's Creative Commons licence, unless indicated otherwise in a credit line to the material. If material is not included in the article's Creative Commons licence and your intended use is not permitted by statutory regulation or exceeds the permitted use, you will need to obtain permission directly from the copyright holder. To view a copy of this licence, visit http://creativecommons.org/licenses/by/4.0/.

\section{References}

1. C.H. Crisosto, G.M. Crisosto, P. Metheney, Consumer acceptance of 'Brooks' and 'Bing' cherries is mainly dependen on fruit SSC and visual color. Postharvest Biol. Technol. 28(1), 159-167 (2003). https://doi.org/10.1016/S0925-5214(02)00173-4

2. G.S. Romano, E.D. Cittadini, B. Pugh, R. Schouten, Sweet cherry quality in the horticultural production chain. Stewart Postharvest Rev. 6(2), 1-9 (2006). https://doi.org/10.2212/ spr.2006.6.2

3. M. Serrano, D. Martinez-Romero, S. Castillo, F. Guillén, D. Valero, The use of natural antifungal compounds improves the beneficial effect of MAP in sweet cherry storage. Innov. Food Sci. Emerg. Technol. 6, 115-123 (2005). https://doi.org/10.1016/j.ifset .2004.09.001

4. M.J. Giménez, J.M. Valverde, D. Valero, F. Guillén, D. MartínezRomero, M. Serrano, S. Castillo, Quality and antioxidant properties on sweet cherries as affected by preharvest salicylic and acetylsalicylic acids treatments. Food Chem. 160, 226-232 (2014). https://doi.org/10.1016/j.foodchem.2014.03.107

5. L. Jakobek, M. Šeruga, S. Voća, Z. Šindrak, N. Dobričević, Flavonol and phenolic acid composition of sweet cherries (cv. Lapins) produced on six different vegetative rootstocks. Sci. Hortic. 123(1), 23-28 (2009)

6. H.E. Khoo, A. Azlan, S.T. Tang, S.M. Lim, Anthocyanidins and anthocyanins: colored pigments as food, pharmaceutical ingredients, and the potential health benefits. Food Nutr. Res 61(1), 1361779 (2017). https://doi.org/10.1080/16546628.2017.13617 79

7. A.A. Wani, P. Singh, K. Gul, M.H. Wani, H.C. Langowski, Sweet cherry (Prunus avium): critical factors affecting the composition and shelf life. Food Packag. Shelf Life. 1, 86-99 (2014). https:// doi.org/10.1016/j.fps1.2014.01.005

8. M. Linke, W.B. Herppich, M. Geyer, Green peduncles may indicate postharvest freshness of sweet cherries. Postharvest Biol. Technol. 58, 135-141 (2010). https://doi.org/10.1016/j.postharvbi o.2010.05.014

9. P. Chełpiński, I. Ochmian, P. Forczmański, Sweet cherry skin colour measurement as an non-destructive indicator of fruit maturity. Acta Univ. Cibiniensis Series E: Food Technol. 23(2), 157-166 (2019). https://doi.org/10.2478/aucft-2019-0019

10. V. Overbeck, M. Schmitz, M. Blanke, Non-destructive sensorbased prediction of maturity and optimum harvest date of sweet cherry fruit. Sensors. 17(2), 277 (2017). https://doi.org/10.3390/ s17020277

11. J. Xing, D. Guyer, D. Ariana, R. Lu, Determining optimal wavebands using genetic algorithm for detection of internal insect infestation in tart cherry. Sens. Instrumen. Food Qual. 2, 161-167 (2008). https://doi.org/10.1007/s11694-008-9047-z

12. O. Esturk, Z. Ayhan, M.A. Ustunel, Modified atmosphere packaging of "Napoleon" cherry: effect of packaging material and storage time on physical, chemical, and sensory quality. Food Bioproc. Technol. 5, 1295-1304 (2012). https://doi.org/10.1007/ s11947-011-0561-3 
13. V. Usenik, F. Stampar, M.M. Petkovsek, D. Kastelec, The effect of fruit size and fruit colour on chemical composition in 'Kordia' sweet cherry (Prunus avium L). J. Food Comp. Anal. 38, 121-130 (2015). https://doi.org/10.1016/j.jfca.2014.10.007

14. C.H. Crisosto, G.M. Crisosto, M.A. Ritenour, Testing the reliability of skin color as an indicator of quality for early season 'Brooks' (Prunus avium L.) cherry. Postharvest Biol. Technol. 24, 147-154 (2002). https://doi.org/10.1016/S0925-5214(01)00190-9

15. B. Gonçalves, A.P. Silva, J. Moutinho-Pereira, E. Bacelar, E. Rosa, A.S. Meyer, Effect of ripeness and postharvest storage on the evolution of colour and anthocyanins in cherries (Prunus avium L.). Food Chem. 103(3), 976-984 (2007). https://doi.org/10.1016/j. foodchem.2006.08.039

16. Q. Wang, H. Wang, L. Xie, Q. Zhang, Outdoor color rating of sweet cherries using computer vision. Comp. Electron. Agric. 87, 113-120 (2012). https://doi.org/10.1016/j.compag.2012.05.010

17. S. Sharma, K. Dhalsamant, P.P. Tripathy, Application of computer vision technique for physical quality monitoring of turmeric slices during direct solar drying. J. Food Meas. Charact. 13, 545-558 (2019). https://doi.org/10.1007/s11694-018-9968-0

18. H. Zhao, B. Wang, K. Cui, J. Cao, W. Jiang, Improving postharvest quality and antioxidant capacity of sweet cherry fruit by storage at near-freezing temperature. Sci. Hortic. 246, 68-78 (2019). https://doi.org/10.1016/j.scienta.2018.10.054

19. M. Linke, M. Geyer, Condensation dynamics in plastic film packaging of fruit and vegetables. J. Food Eng. 116(1), 144-154 (2013). https://doi.org/10.1016/j.jfoodeng.2012.11.026

20. G.G. Bovi, O.J. Caleb, M. Linke, C. Rauh, P.V. Mahajan, Transpiration and moisture evolution in packaged fresh horticultural produce and the role of integrated mathematical models: a review. Biosys. Eng. 150, 24-39 (2016). https://doi.org/10.1016/j.biosy stemseng.2016.07.013

21. G.G. Bovi, O.J. Caleb, E. Klaus, F. Tintchev, C. Rauh, P.V. Mahajan, Moisture absorption kinetics of FruitPad for packaging of fresh strawberry. J. Food Eng. 223, 248-254 (2018). https://doi. org/10.1016/j.jfoodeng.2017.10.012

22. F. Li, X. Zhang, B. Song, J. Li, Z. Shang, J. Guan, Combined effects of 1-MCP and MAP on the fruit quality of pear (Pyrus bretschneideri Reld cv Laiyang) during cold storage. Sci. Hortic. 164, 544-551 (2013). https://doi.org/10.1016/j.scien ta.2013.10.018

23. G. Rux, P.V. Mahajan, M. Linke, A. Pant, S. Sängerlaub, O.J. Caleb, M. Geyer, Humidity-regulating trays: moisture absorption kinetics and applications for fresh produce packaging. Food Bioproc. Technol. 9(4), 709-716 (2016)

24. J.W. Eaton, D. Bateman, S. Hauberg, R. Wehbring, GNU Octave version 4.4.1 manual: a high-level interactive language for numerical computations (2018). URL https://www.gnu.org/softw are/octave/doc/v4.4.1/

25. B.-H. Mevik, R. Wehrens, The pls Package: Principal Component and Partial Least Squares Regression in R. J. Stat. Softw. 18(2), 1-24 (2007). https://doi.org/10.18637/jss.v018.i02

26. F. Kappel, P. Toivonen, D.L. McKenzie, S. Stan, Storage characteristics of new sweet cherry cultivars. HortScience 37(1), 139-143 (2002). https://doi.org/10.21273/HORTSCI.37.1.139

27. M. Linke, W.B. Herppich, M. Geyer, Verbesserung der Kurzzeitlagerung von Kirschen. Landtechnik 57, 278-279 (2002)

28. G. Tsaniklidis, M. Kafkaletou, C. Delis, E. Tsantili, The effect of postharvest storage temperature on sweet cherry (Prunus avium L.) phenolic metabolism and colour development. Sci. Hortic. 225, 751-756 (2017). https://doi.org/10.1016/j.scien ta.2017.08.017

29. G. Muskovics, J. Felföldi, E. Kovács, R. Perlaki, T. Kállay, Changes in physical properties during fruit ripening of Hungarian sweet cherry (Prunus avium L) cultivars. Postharvest Biol. Technol. 40, 56-63 (2006). https://doi.org/10.1016/j.postharvbi 0.2005 .12 .007

30. L. Baranyai, A. Szepes, Analysis of fruit and vegetable surface color. Mach. Gr. Vis. 11(2/3), 351-361 (2002)

31. S. Escribano, W.V. Biasi, R. Lerud, D.C. Slaughter, E.J. Mitcham, Non-destructive prediction of soluble solids and dry matter content using NIR spectroscopy and its relationship with sensory quality in sweet cherries. Postharvest Biol. Technol. 128, 112-120 (2017). https://doi.org/10.1016/j.postharvbio.2017.01.016

32. A.V. McGlone, R.B. Jordan, P.J. Martinsen, Vis/NIR estimation at harvest of pre- and post-storage quality indices for 'Royal Gala' apple. Postharvest Biol. Technol. 25(2), 135-144 (2002). https:// doi.org/10.1016/S0925-5214(01)00180-6

33. S. Srivastava, S. Sadistap, Non-destructive sensing methods for quality assessment of on-tree fruits: a review. Food Meas. 12, 497-526 (2018). https://doi.org/10.1007/s11694-017-9663-6

34. C.N. Nunes, J.P. Emond, Relationship between weight loss and visual quality of fruits and vegetables. Proc. Florida State Horticul. Soc. 2007(120), 235-245 (2007)

35. S.P. Dawange, S.K. Dash, L.M. Bal, M.K. Panda, Quality of minimally processed carrots in perforation-mediated modifiedatmosphere packaging (PM-MAP). J. Food Meas. Charact. 10(4), 746-754 (2016). https://doi.org/10.1007/s11694-016-9359-3

Publisher's Note Springer Nature remains neutral with regard to jurisdictional claims in published maps and institutional affiliations. 